Book of Value 






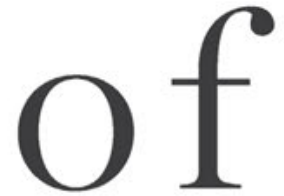

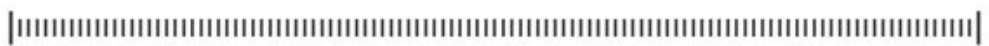
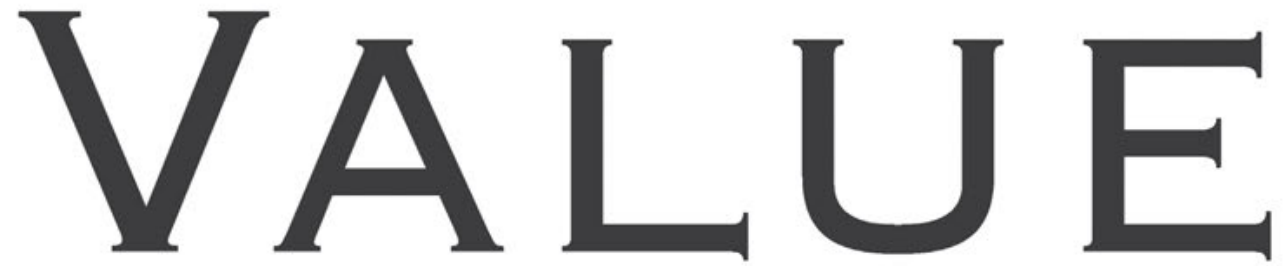

|

\section{The FINE ART of INVESTING WISELY}

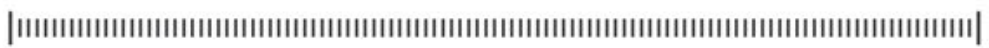

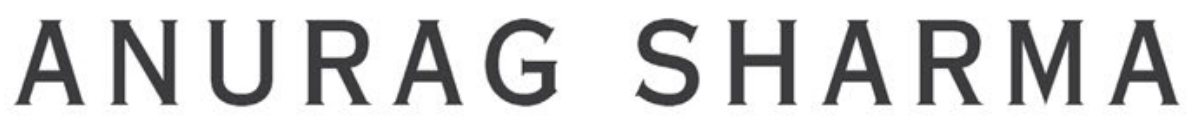

\section{$4 \underset{\text { Publishing }}{\text { Columbia Business School }}$}


Columbia University Press

Publishers Since 1893

New York Chichester, West Sussex

cup.columbia.edu

Copyright (C) 2016 Anurag Sharma

All rights reserved.

Library of Congress Cataloging-in-Publication Data

Names: Sharma, Anurag, author.

Title: Book of value : the fine art of investing wisely / Anurag Sharma.

Description: New York : Columbia University Press, [20I6] |

Includes bibliographical references and index.

Identifiers: LCCN 20I 505 I334 | ISBN 978023 I I 75425 (cloth : alk. paper)

Subjects: LCSH: Investments. | Portfolio management. |

Finance-Psychological aspects.

Classification: LCC HG452 I .S475 2016 | DDC 332.6-dc23

LC record available at http://lccn.loc.gov/20I 505 I 334

Columbia University Press books are printed on permanent and durable acid-free paper.

Printed in the United States of America.

c IO 98765432 I

Cover design: Noah Arlow 
For Mary, Helen, and Monika.

In memory of my father, Mahendra Bhushan 
